\title{
The 6 thalamic regions: surgical approaches to thalamic cavernous malformations, operative results, and clinical outcomes
}

\author{
Leonardo Rangel-Castilla, MD, and Robert F. Spetzler, MD \\ Division of Neurological Surgery, Barrow Neurological Institute, St. Joseph's Hospital and Medical Center, Phoenix, Arizona
}

OBJECT The ideal surgical approach to thalamic cavernous malformations (CMs) varies according to their location within the thalamus. To standardize surgical approaches, the authors have divided the thalamus into 6 different regions and matched them with the corresponding surgical approach.

METHODS The regions were defined as Region 1 (anteroinferior), Region 2 (medial), Region 3 (lateral), Region 4 (posterosuperior), Region 5 (lateral posteroinferior), and Region 6 (medial posteroinferior). The senior author's surgical experience with 46 thalamic CMs was reviewed according to this classification. An orbitozygomatic approach was used for Region 1; anterior ipsilateral transcallosal for Region 2; anterior contralateral transcallosal for Region 3; posterior transcallosal for Region 4; parietooccipital transventricular for Region 5; and supracerebellar-infratentorial for Region 6.

RESULTS Region 3 was the most common location (17 [37\%]). There were 5 CMs in Region $1(11 \%), 9$ in Region 2 $(20 \%)$, 17 in Region $3(37 \%), 3$ in Region $4(6 \%)$, 4 in Region $5(9 \%)$, and 8 in Region $6(17 \%)$. Complete resection was achieved in all patients except for 2 , who required a second-stage operation. The mean follow-up period was 1.7 years (range 6 months-9 years). At the last clinical follow-up, 40 patients (87\%) had an excellent or good outcome (modified Rankin Scale [mRS] scores $0-2$ ) and 6 (13\%) had poor outcome (mRS scores 3-4). Relative to their preoperative condition, 42 patients $(91 \%)$ were unchanged or improved, and $4(9 \%)$ were worse.

CONCLUSIONS The authors have presented the largest series reported to date of surgically treated thalamic CMs, achieving excellent results using this methodology. In the authors' experience, conceptually dividing the thalamus into 6 different regions aids in the selection of the ideal surgical approach for a specific region.

http://thejns.org/doi/abs/10.3171/2014.11.JNS14381

KEY WORDS thalamus; cavernous malformation; thalamic regions; vascular disorders; surgical approaches

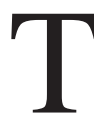
He thalamus is located in the center of the lateral ventricles rostral to the brainstem. Because it is surrounded by vital neurovascular structures, the surgical approach to it can be challenging. The thalamus is intimately related to the basal ganglia, internal capsule, midbrain, foramen of Monro, stria terminalis, thalamostriate vein, and the internal cerebral veins. ${ }^{25}$

Cavernous malformations (CMs) of the thalamus and basal ganglia are relatively rare lesions that can cause devastating neurological deficits., ${ }^{314-16,21}$ Because of the rarity of these lesions, descriptions of their natural history, ideal treatment, surgical approaches, complications, and outcomes have been limited to case reports and small se- ries. ${ }^{3,5,7-9,14-16,19-21,23,24,27,29}$ The initial surgical approach and resection of thalamic $\mathrm{CMs}$ are directly associated with the risks of creating a new or worsening neurological deficit. ${ }^{8}$ The benefit of surgery must be weighed against these risks. ${ }^{3}$ Lately, skull base approaches have been described for CMs of the brainstem based on the 2-point method., 1,2,46 In contrast, $\mathrm{CMs}$ of the basal ganglia and thalamus have been given scant attention. Some neurosurgeons still consider these lesions inoperable, or as requiring much deliberation for selection of the best surgical approach. An extensive experience with deep vascular lesions has helped us to redefine traditional approaches to thalamic CMs.

Cavernous malformations can be situated anywhere

ABBREVIATIONS ACT = anterior contralateral interhemispheric transcallosal; $\mathrm{AIT}=$ anterior ipsilateral interhemispheric transcallosal; $\mathrm{CM}=$ cavernous malformation; $\mathrm{DVA}$ = developmental venous anomaly; GTR = gross-total resection; $\mathrm{mRS}$ = modified Rankin Scale; OZ = orbitozygomatic; PIT = posterior interhemispheric transcallosal; POT = parietooccipital transventricular; SCIT = suboccipital supracerebellar infratentorial.

SUBMITTED February 17, 2014. ACCEPTED November 5, 2014.

INCLUDE WHEN CITING Published online May 29, 2015; DOI: 10.3171/2014.11.JNS14381.

DISCLOSURE The authors report no conflict of interest concerning the materials or methods used in this study or the findings specified in this paper. 
within the thalamus. We have found that each section of the thalamus has a specific and different surgical approach and corridor. ${ }^{3,5,8,15,19}$ In this paper, we classify the thalamus into 6 different regions based on the anatomy of, and the most suitable surgical approach for, that region (Fig. 1). This classification has been applied to 46 patients with thalamic CMs to systematize our surgical approach to these lesions and to present our surgical results and patients' long-term outcomes.

\section{Methods}

\section{The 6 Anatomical Thalamic Regions}

Region 1 (Anteroinferior)

Region 1 houses the inferior anterior nuclei and the ventral anterior nucleus of the thalamus. The superior and medial margins of this region are formed by Region 2 , and the posterior margin is formed by Region 3. The anterolateral borders are formed by the genu and posterior limb of the internal capsule. The inferior margin is formed by the anterior perforated substance, which lies immediately above the internal carotid artery bifurcation (Figs. 1 and 2). ${ }^{25,31}$

\section{Region 2 (Medial)}

Region 2 contains the superior anterior nuclei, the medial nuclei, and the medial portion of the centromedial nucleus of the thalamus. It consists of upper (thalamic) and lower (hypothalamic) portions that project into the lateral and third ventricles, respectively. These 2 portions are separated by the hypothalamic sulcus. The upper portion is limited anteriorly by the thalamostriate vein just behind the foramen of Monro; its medial margin is formed by the superior choroidal vein, the choroid plexus, and the foramen of Monro; and its lateral margin is formed by the internal medullary lamina and Region 3 . The inferior portion of Region 2 projects into and forms the lateral wall of the third ventricle. This portion can be accessed between the fornices or through the foramen of Monro or the tela choroidea. The striae medullaris thalami extend along the superomedial border of the thalamus from the foramen of Monro to the habenular commissure. The massa intermedia connects the opposing surfaces of the thalamus, and its presence is variable. The columns of the fornix form a prominence in the lateral walls of the third ventricle below the foramen of Monro and sink below the surface inferiorly (Figs. 1 and 3). ${ }^{25}$

\section{Region 3 (Lateral)}

Region 3 houses the lateral nuclei (i.e., the ventral anterior, ventral lateral, ventral posterior, lateral dorsal, and lateral posterior nuclei). It is limited medially by the internal medullary lamina and Region 2, and laterally by the genu and posterior limb of the internal capsule (Figs. 1 and 4). ${ }^{25,34}$

The posterior thalamus (pulvinar) is intimately associated with 3 different compartments, making its surgical approach more challenging. For this reason we have divided the pulvinar into 3 different regions (Regions 4, 5, and 6), as described below. ${ }^{17,34}$
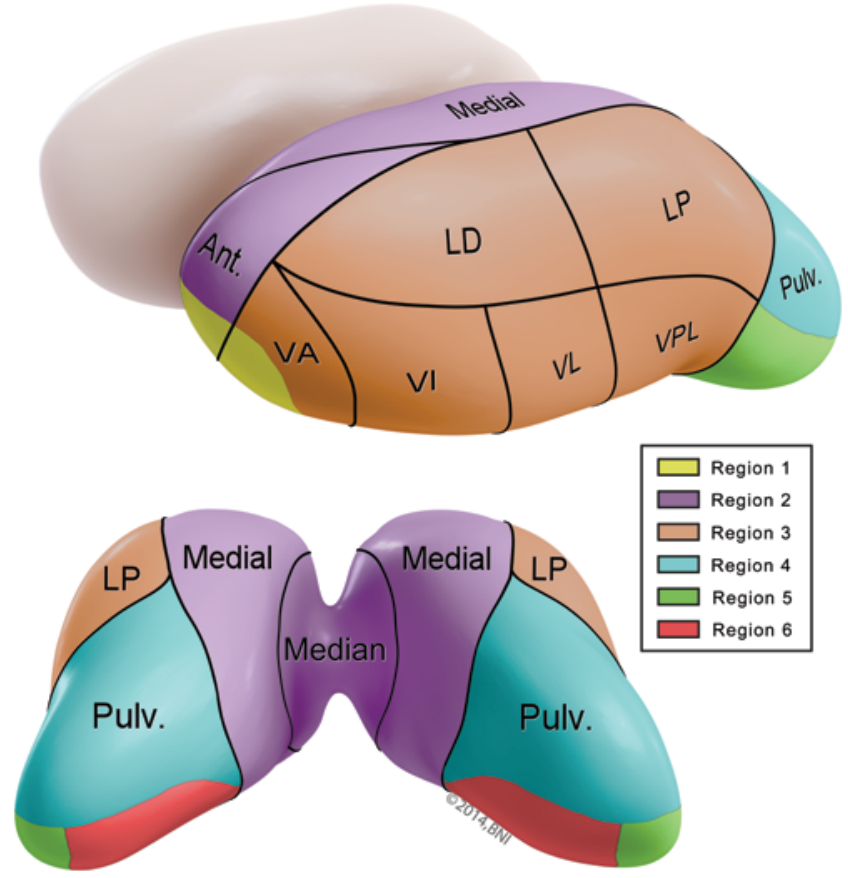

FIG. 1. Artist's illustration depicting the 6 thalamic regions. Ant $=$ anterior; $\mathrm{LD}=$ lateral dorsal; $\mathrm{LP}=$ lateral posterior; Pulv = pulvinar; $\mathrm{VA}=$ ventral anterior; $\mathrm{VI}=$ ventral intermediate; $\mathrm{VL}=$ ventral lateral, $\mathrm{VPL}=$ ventral posterior lateral. Copyright Barrow Neurological Institute, Phoenix, Arizona. Published with permission.

\section{Region 4 (Posterosuperior)}

Region 4 houses the crus of the fornix and the tail of the caudate nucleus. Its anterior limit is formed by Regions 2 and 3. Its roof is formed by the lateral ventricle and the corpus callosum. Posteriorly, it faces the upper part of the ambient and quadrigeminal cisterns. Its lateral aspect is bordered by the posterior limb of the internal capsule (Figs. 1 and 5). 25,34

\section{Region 5 (Lateral Posteroinferior)}

The anterior limit of Region 5 is also formed by Regions 2 and 3. Its lateral limit is formed by the internal capsule and the caudate nucleus. It projects into the anterior wall of the atrium of the lateral ventricle. Within the ventricle, it is limited medially by the choroid plexus and laterally by the tail of the caudate nucleus. Its medial limit is formed by Region 6 . It continues inferiorly as the midbrain (Figs. 1 and 6)..$^{25,34}$

\section{Region 6 (Medial Posteroinferior)}

The anterior limit of Region 6 is also formed by Regions 2 and 3. It projects into the wing of the ambient cistern. Medially, it is closely related with the lateral habenular nucleus, habenular commissure, and pineal gland. Its lateral limit is formed by Region 5. Like Region 5, it also continues inferiorly as midbrain (Figs. 1 and 7).25,34

\section{Patient Population}

During a 5-year period, a total of 310 patients with supratentorial CMs were treated surgically at Barrow Neurological Institute, Phoenix, Arizona, by the same neurosur- 

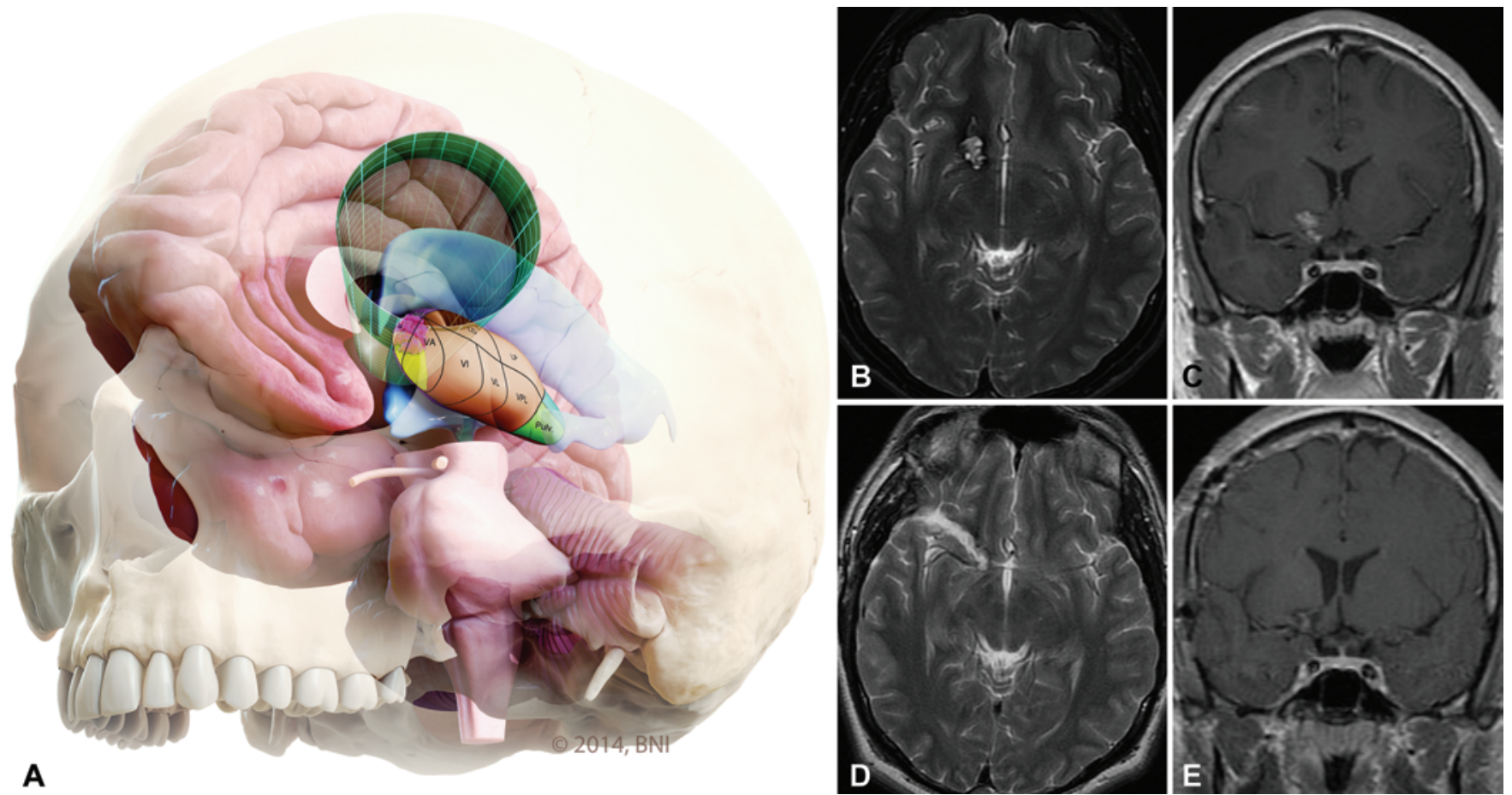

FIG. 2. Region 1-anteroinferior thalamus. Artist's illustration (A) demonstrating the surgical trajectory orbitozygomatic (OZ) to thalamic Region 1. Preoperative MRI obtained with contrast: (B) axial T2-weighted and (C) coronal T1-weighted studies showing an enhancing lesion at the anteroinferior part of the thalamus consistent with a thalamic CM. Immediate postoperative MRI obtained with contrast: (D) axial T2-weighted and (E) coronal T1-weighted studies demonstrating GTR of the CM after an OZ transsylvian supracarotid-infrafrontal approach. Figure 2A copyright Barrow Neurological Institute, Phoenix, Arizona. Published with permission.
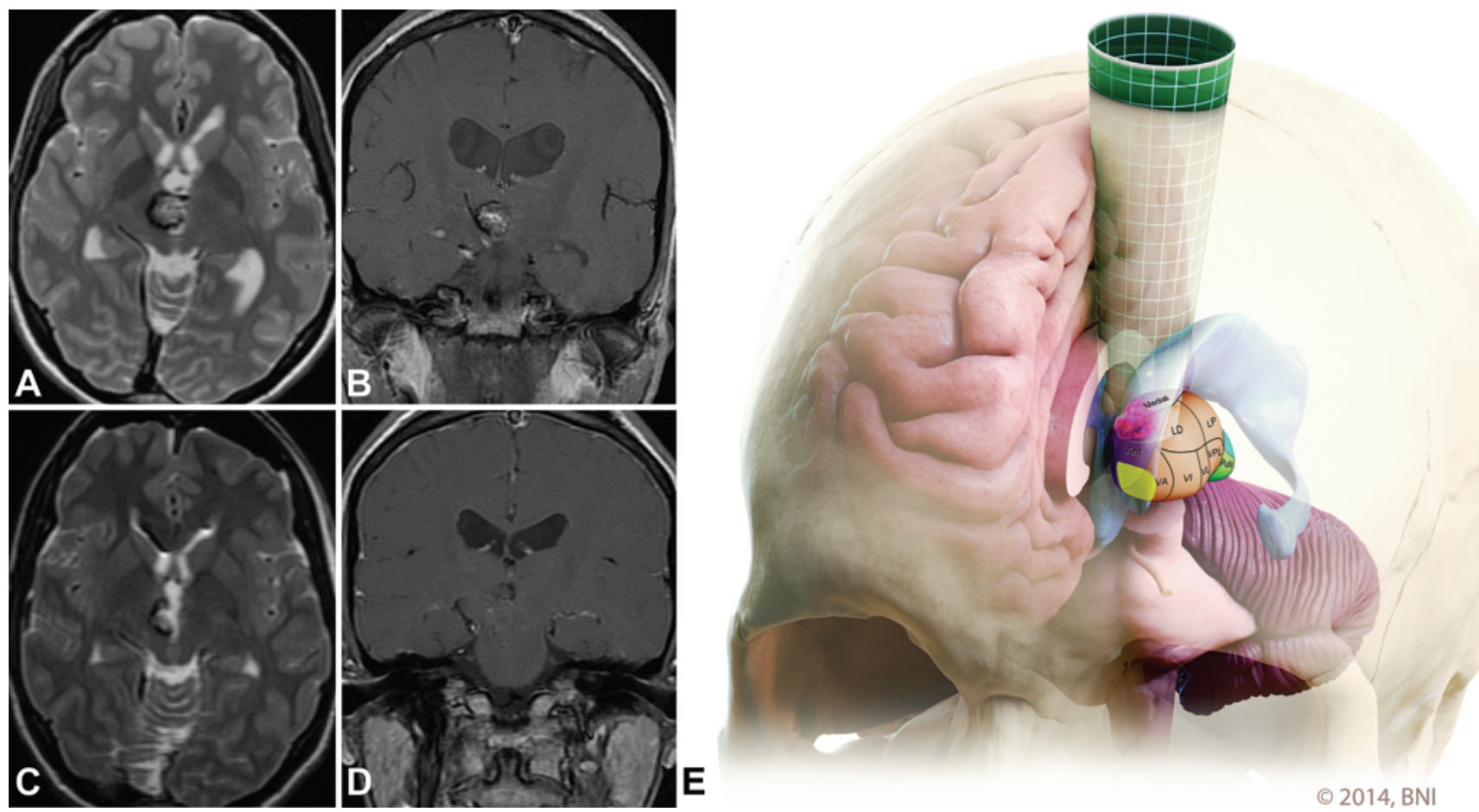

FIG. 3. Region 2-medial thalamus. Preoperative MRI obtained with contrast: (A) axial T2-weighted and (B) coronal T1-weighted studies showing an enhancing lesion at the medial part of the thalamus consistent with a thalamic $\mathrm{CM}$. The lesion protrudes into the third ventricle, causing obstructive hydrocephalus. Immediate postoperative MRI studies obtained with contrast: (C) axial T2weighted and (D) coronal T1-weighted studies demonstrating GTR of the CM after an AIT approach. The lesion is no longer causing obstruction at the third ventricle, with resolution of the hydrocephalus. Artist's illustration (E) demonstrating the AIT approach to thalamic Region 2. Figure 3E copyright Barrow Neurological Institute, Phoenix, Arizona. Published with permission. 

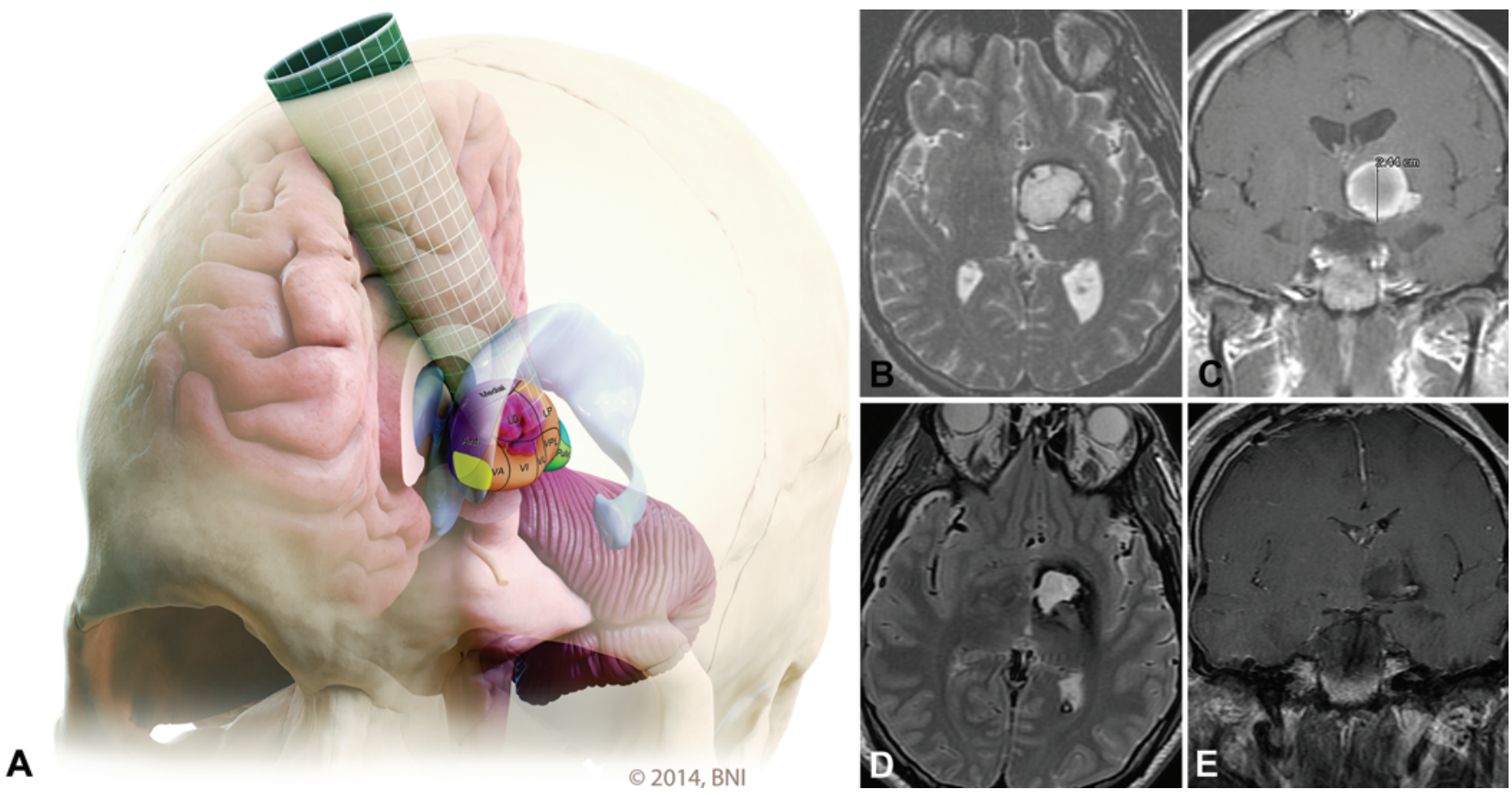

FIG. 4. Region 3-lateral thalamus. Artist's illustration (A) demonstrating the ACT approach to thalamic Region 3. Preoperative MRI obtained with contrast: (B) axial T2-weighted and (C) coronal T1-weighted studies showing a large enhancing lesion at the lateral part of the thalamus, consistent with a thalamic CM. Immediate postoperative MRI obtained with contrast: (D) axial T2weighted and (E) coronal T1-weighted studies demonstrating GTR of the CM. Figure 4A copyright Barrow Neurological Institute, Phoenix, Arizona. Published with permission.

geon (R.F.S.) and recorded in a prospective database. The database was searched for patients with thalamic CMs, and 46 patients were identified and included in this study.

There were 24 women $(52 \%)$ and 22 men (48\%) with a mean age of 36 years (range 7-64 years) (Table 1). Of the 46 patients, $27(59 \%)$ presented with hemorrhage, which was intraparenchymal in $21(78 \%)$ and intraventricular in $6(22 \%)$ patients. Ten patients $(22 \%)$ presented with contralateral body numbness and/or paresthesia. Three patients $(6 \%)$ presented with diplopia related to cranial nerve weakness of the oculomotor, trochlear, or abducens nerves. Two patients (4\%) presented with contralateral facial nerve paralysis. Nineteen patients $(41 \%)$ presented with headache. Five patients with intraventricular hemorrhage also presented with hydrocephalus and required a ventriculoperitoneal shunt. Twelve patients $(26 \%)$ had previously undergone surgery at other centers and were referred to us due to incomplete resection. For those CMs presenting with hemorrhage, surgery was performed immediately after the acute episode.

\section{Characteristics of CMs}

We systematically reviewed patients' CT and MRI studies, operative reports, intraoperative videos, and the surgeon's notes to classify thalamic CMs according to the 6 different locations. Large CMs that occupied more than one region were classified according to the location of the center of the lesion. Some CMs extended into the ventricle, laterally into the internal capsule, or inferiorly into the midbrain or cerebral peduncle. Twenty-six CMs
(57\%) were located on the left side. The mean CM diameter was $21.23 \mathrm{~mm}$ (range 5-45 mm). Asymptomatic small CMs $(<5 \mathrm{~mm}$ ) within the thalamus proper (no pial surface or accessible surface) were managed conservatively with follow-up imaging.

\section{Outcome Evaluation}

Neurological outcome was assessed using the modified Rankin Scale (mRS). Neurological assessments were performed by chief neurosurgical residents and cerebrovascular fellows under the supervision of the senior neurosurgeon, preoperatively, postoperatively, and on a yearly basis after treatment. Follow-up information was obtained during routine clinical visits and/or telephone interviews. Good outcomes were defined as a final mRS score of $0-2$, and poor outcomes were defined as a final mRS score greater than 2. Postoperative MRI studies were obtained within 24 hours after surgery to assess for residual malformation, and on a yearly basis to assess for recurrence.

\section{Results}

\section{Anatomy of Thalamic CMs}

The most common location was the lateral thalamus (Region 3), and the least common was the posterosuperior thalamus (Region 4). Developmental venous anomalies (DVAs) were seen on MR imaging in $68 \%$ of patients; however, DVAs were intraoperatively observed in all patients. Eleven CMs (24\%) were classified as large ( $\geq 25$ $\mathrm{mm})$ and $3(6 \%)$ were classified as giant $(\geq 40 \mathrm{~mm})$. The 

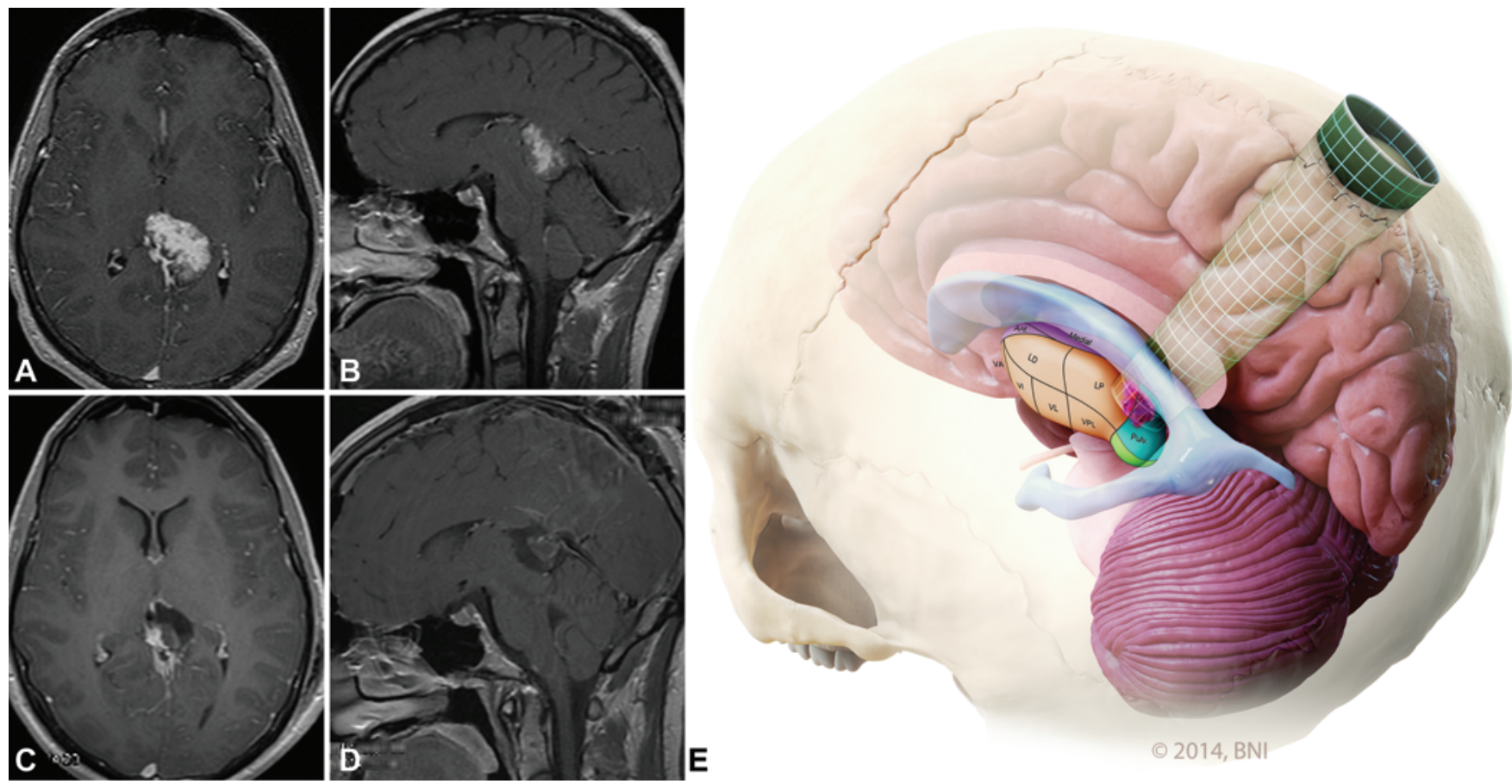

FIG. 5. Region 4-posterosuperior thalamus. Preoperative MRI obtained with contrast: (A) axial and (B) sagittal T1-weighted studies showing an enhancing lesion at the posterosuperior part of the thalamus; the lesion extends into the quadrigeminal cistern and contralateral thalamus. Postoperative MRI obtained with contrast: (C) axial and (D) sagittal T1-weighted studies demonstrating GTR of the vascular lesion after a PIT approach. Artist's illustration (E) demonstrating the PIT approach to thalamic Region 4. Figure 5E copyright Barrow Neurological Institute, Phoenix, Arizona. Published with permission.
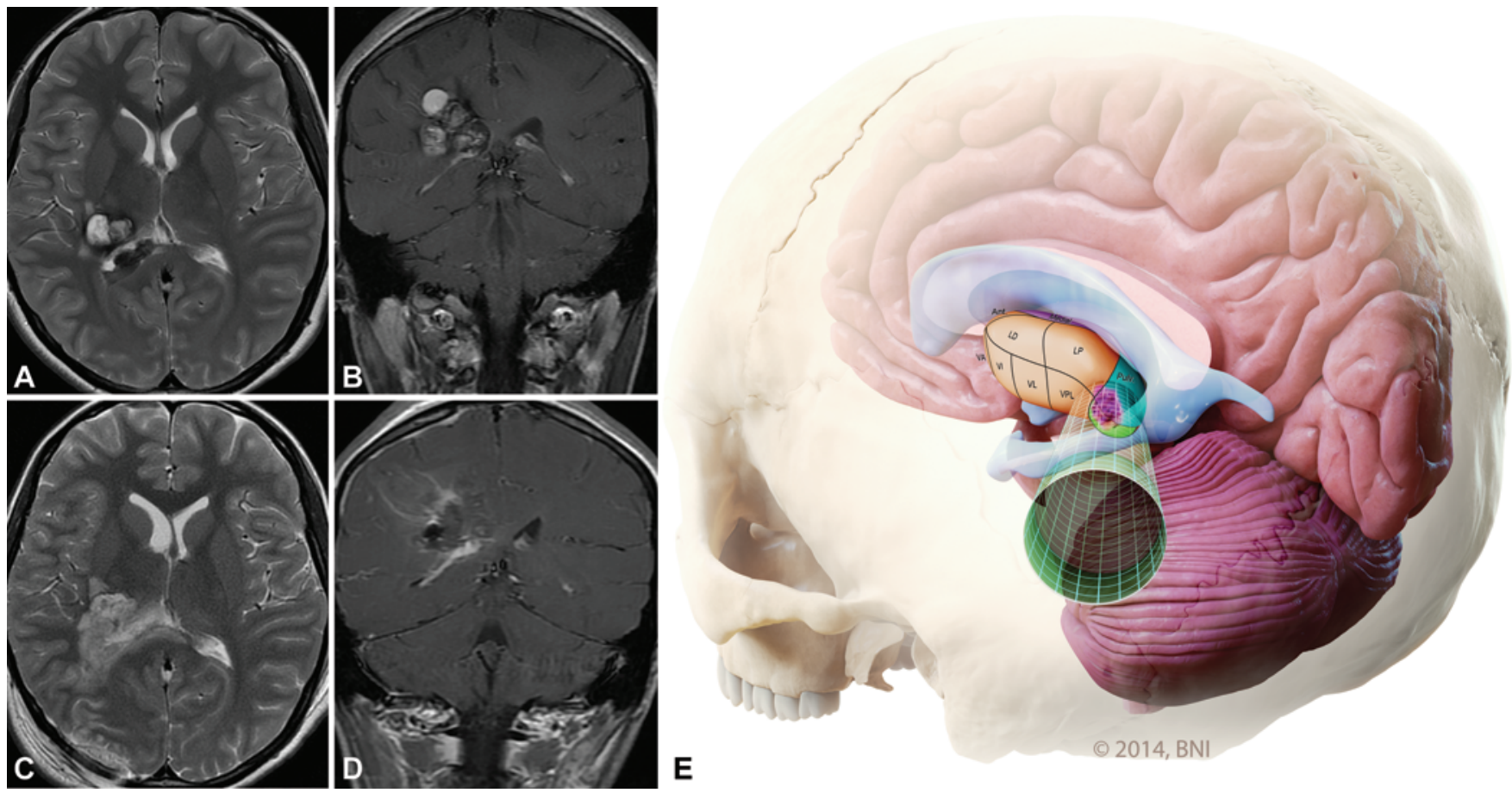

FIG. 6. Region 5-lateral posteroinferior thalamus. Preoperative MRI obtained with contrast: (A) axial T2-weighted and (B) coronal T1-weighted studies showing a large enhancing lesion at the lateral posteroinferior part of the thalamus consistent with a thalamic CM. Immediate postoperative MRI obtained with contrast: (C) axial T2-weighted and (D) coronal T1-weighted studies demonstrating GTR of the CM after a POT approach. Artist's illustration (E) demonstrating the POT approach to thalamic Region 5. Figure 6E copyright Barrow Neurological Institute, Phoenix, Arizona. Published with permission. 

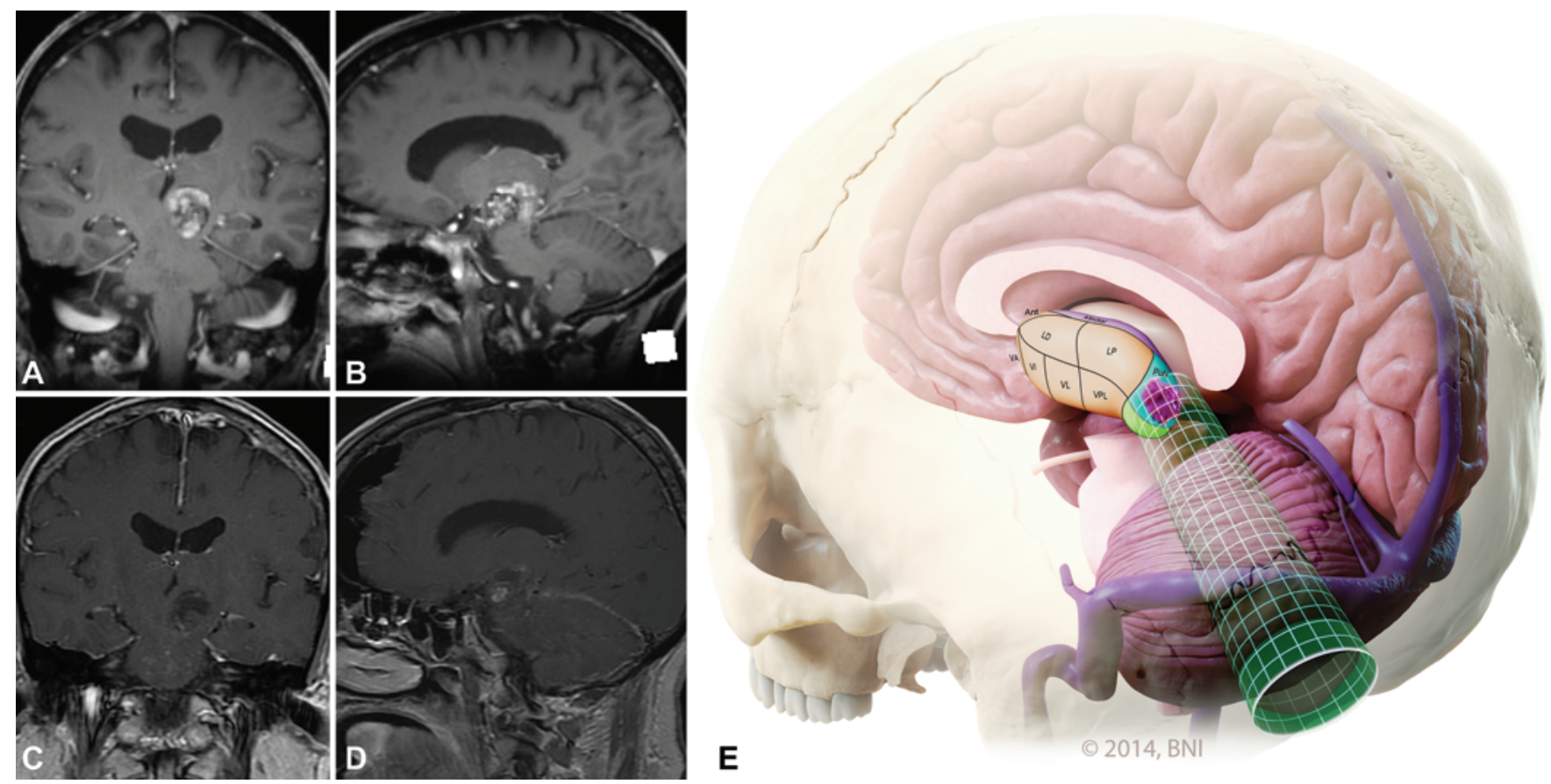

FIG. 7. Region 6-medial posteroinferior thalamus. Preoperative MRI obtained with contrast: (A) axial T2-weighted and (B) sagittal T1-weighted studies showing an enhancing lesion at the medial posteroinferior part of the thalamus consistent with a thalamic CM. Immediate postoperative MRI obtained with contrast: (C) axial T2-weighted and (D) sagittal T1-weighted studies demonstrating GTR of the CM after an SCIT approach. Artist's illustration (E) demonstrating the SCIT approach to thalamic Region 6. Figure 7E copyright Barrow Neurological Institute, Phoenix, Arizona. Published with permission.

location of these large or giant CMs was assigned according to the location of the center of the CM (Table 2).

\section{Operative Strategies and Approaches}

The 6 procedures used were the modified orbitozygomatic (OZ); anterior ipsilateral interhemispheric transcallosal (AIT) (including the transventricular, transforaminal,

\section{TABLE 1. Characteristics of 46 patients with thalamic $\mathrm{CMs}^{*}$}

\begin{tabular}{lc}
\hline \multicolumn{1}{c}{ Characteristic } & \multicolumn{1}{c}{ Value } \\
\hline No. of thalamic CMs & 46 \\
\hline Mean age in yrs (range) & $36.3(7-64)$ \\
\hline Sex & $22(48)$ \\
\hline Male & $24(52)$ \\
\hline Female & \\
\hline Clinical presentation & $19(41)$ \\
\hline Headache & $27(59)$ \\
\hline Hemorrhage & $21(78)$ \\
\hline Intraparenchymal & $6(22)$ \\
\hline Intraventricular & $5(11)$ \\
\hline Hydrocephalus & $10(22)$ \\
\hline Sensory problems-numbness, paresthesias, pain & $3(6)$ \\
\hline CN III/IV/VI dysfunction (diplopia) & $2(4)$ \\
\hline CN VII weakness & $12(26)$ \\
\hline Previous surgery \& incomplete resection
\end{tabular}

$\mathrm{CN}=$ cranial nerve.

* Unless otherwise specified, values are expressed as number (\%). and transchoroidal variations); anterior contralateral interhemispheric transcallosal (ACT); posterior interhemispheric transcallosal (PIT); parietooccipital transventricular (POT); and suboccipital supracerebellar infratentorial (SCIT) approaches. An OZ craniotomy with a transsylvian supracarotid-infrafrontal dissection was used for Region 1 (5 CMs, 11\%). The AIT approach was used for Region 2 (9 CMs, 20\%). Of the AIT approaches in Region 2, the AIT transventricular variation was used on $2 \mathrm{CMs}(4 \%)$ located in the superior medial portion of the thalamus, and the AIT transforaminal (3 CMs, 6\%) and AIT transchoroidal (4 CMs, 9\%) variations were used to access CMs of the lateral wall of the third ventricle. The ACT approach was the most common procedure (17 CMs, 37\%) and was used for CMs in Region 3 (Video 1).

VIDEO 1. Clip showing the procedure in a 42-year-old man with a history of left upper- and lower-extremity paresthesias. Preoperative $\mathrm{MRI}$ of the brain showed a CM at the right thalamus. The location of the lesion was at Regions 2 and 3 . The recommendation was for the patient to undergo resection through an ACT transchoroidal approach. The patient was positioned supine with the head rotated to the contralateral (left) side of the lesion (right). A frontal craniotomy two-thirds in front and one-third behind the coronal suture was done. Interhemispheric dissection was performed until the corpus callosum was found. A corpus callosotomy was performed and the left lateral ventricle was entered. The choroidal fissure was opened lateral to the choroid plexus. The third ventricle was entered and hemosiderin-stained white matter was encountered, leading to the $\mathrm{CM}$. This was confirmed with neuronavigation. The right lateral wall of the third ventricle was entered and the malformation was excised. Lighted suction cannulas provided better visualization at this deep location. After the resection was completed, a final inspection and hemostasis of the surgical cavity was done. No retractors were used 
during the entire procedure. Immediate postoperative MRI showed GTR. The patient remained neurologically intact and was discharged home 2 days after surgery. Copyright Barrow Neurological Institute, Phoenix, Arizona. Published with permission. Click here to view with Media Player. Click here to view with Quicktime.

The PIT approach was used for Region 4 (3 CMs, 6\%); the POT for Region 5 (4 CMs, 9\%); and the SCIT for Region 6 (8 CMs, 17\%) (Table 2, Video 2).

VIDEO 2. Clip showing the procedure in a 57-year-old man with headaches and an MRI study of the brain that showed a left posterior thalamus CM. The location of the lesion was at Region 6. The recommendation was for the patient to undergo resection through a lateral suboccipital craniotomy and SCIT approach to the posteromedial thalamus. A left side up, park-bench position was used. Neuronavigation was used to confirm the trajectory and craniotomy site. A paramedian suboccipital craniotomy was done. An SCIT dissection was carried down into the ambient cistern. The posterior cerebral artery and the fourth cranial nerve were identified. With neuronavigation guidance, the posterior thalamus was entered. The CM was encountered and excised using a piecemeal technique. After GTR, the cavity was inspected for residual lesion and meticulous hemostasis was performed. The craniotomy was closed routinely. The patient remained neurologically intact and was discharged home 2 days after surgery. Copyright Barrow Neurological Institute, Phoenix, Arizona. Published with permission. Click here to view with Media Player. Click here to view with Quicktime.

Intraoperative neuronavigation and somatosensory and motor evoked potentials were used in all cases. An operative chair, microscope mouthpiece, lighted suction tips, and bipolar electrocautery were also used in all cases.

\section{Surgical Results}

All patients had an immediate postoperative MRI within 24-48 hours of surgery. Complete resection of thalamic CMs was achieved in all but 2 patients. These 2 patients had large $(\geq 25 \mathrm{~mm}) \mathrm{CMs}$, and unexpected residual malformation was seen on postoperative MRI (Table 2). These 2 large CMs were located in the lateral posteroinferior (Region 5) and anteroinferior thalamus (Region 1). Both patients underwent a second-stage surgery to complete the resection; gross-total resection (GTR) was obtained in both patients in the second surgery. None of the DVAs were taken or sacrificed during surgery. There were no major complications related to the procedures. Four minor complications occurred, including 1 small epidural hematoma that was managed conservatively, 1 wound infection requiring long-term antibiotics, and 2 pseudomeningoceles that required surgical repair.

\section{Patient Outcome}

All patients were followed clinically and radiographically for at least 6 months after surgery. The mean followup period was 1.7 years (range 6 months -9 years). There were no deaths. Ten patients (22\%) had temporary worsening of their preoperative symptoms after surgery. Ten patients with preoperative contralateral hemiparesis and/ or hemiparesthesias had worsening of symptoms; 6 recovered over the next 6-8 weeks after surgery. None of the patients were hemiplegic after surgery. Two patients with oculomotor dysfunction also had worsening of symptoms that recovered back to baseline after 8 weeks. In addition, 1 patient with a facial weakness (House-Brackmann Grade
TABLE 2. The 6 thalamic regions and surgical approaches in 46 patients with $\mathrm{CMs}$

\begin{tabular}{clccc}
\hline \multirow{2}{*}{ Region } & \multicolumn{1}{c}{ Location } & Approach & $\begin{array}{c}\text { No. of } \\
\text { CMs }\end{array}$ & Residual \\
\hline 1 & Anteroinferior & OZ & 5 & 1 \\
\hline 2 & Medial & AIT & 9 & 0 \\
\hline 3 & Lateral & ACT & 17 & 0 \\
\hline 4 & Posterosuperior & PIT & 3 & 0 \\
\hline 5 & Lateral posteroinferior & POT & 4 & 1 \\
\hline 6 & Medial posteroinferior & SCIT & 8 & 0 \\
\hline
\end{tabular}

III) had temporary worsening (House-Brackmann Grade V). At the end of the study, 40 patients (87\%) had excellent or good outcomes (mRS scores of 0-2) and $6(13 \%)$ had poor outcomes (mRS scores of 3-4). Relative to their preoperative condition, 42 patients (91\%) were unchanged or improved, and 4 (9\%) were worse. Postoperative transient neurological morbidities were equally distributed in all regions and approaches. There was no single region or approach that had a significantly higher incidence of postoperative transient neurological deficits (Table 3).

\section{Discussion}

Surgical management of thalamic CMs has been described in the literature only in case reports and small series. $3,5,7,8,11,13,20-22,24,27,28,31,32$ Therefore, surgical approaches to the thalamus and expected outcomes are not clear. Our experience with thalamic CMs has demonstrated that favorable results can be achieved with adequate exposure and microsurgical resection. In the present series, all lesions were removed completely in a single surgery, with the exception of 2 patients $(4 \%)$ who required a secondstage operation via the same approach. Transient new deficits and worsening of preexisting neurological deficits were seen in 12 patients (26\%). These temporary deficits were resolved within 6-8 weeks of surgery. There were 4 patients (9\%) with neurological deficits from the CM bleeding that worsened after surgery who had not recovered at the last clinical follow-up visit (Table 3). At a mean follow-up of 1.7 years, symptoms were unchanged or improved in 42 patients (91\%). These results justify an aggressive surgical approach toward thalamic $\mathrm{CMs} .{ }^{33}$

In this report, we describe our surgical experience with 46 thalamic CMs. Until now, no anatomical classification existed for thalamic CMs. Li et al ${ }^{19}$ reported a series of 27 thalamic CMs and mentioned 6 different approaches. The Stanford group recently updated their series of basal ganglia, thalamic, and brainstem CMs (including 16 thalamic lesions); however, differentiations were not made based on location..$^{23}$ We propose a thalamic classification based on anatomical locations and corresponding surgical approaches to each specific location within the thalamus. These approaches have been previously described by us or other experienced vascular neurosurgeons. ${ }^{5,8,11,18,23,28,29,31}$

\section{Region 1 (Anteroinferior)}

Lesions in the anteroinferior thalamus are near the cau- 
TABLE 3. Preoperative and postoperative neurological deficits with respect to $\mathrm{CM}$ location and surgical approach in 46 patients

\begin{tabular}{ccclcc}
\hline Region & Approach & No. of Patients & Initial Neuro Defs & Worsening of Preop Defs Postop & Neuro Defs at End of Study* \\
\hline 1 & OZ & 5 & $1 \mathrm{~h} / \mathrm{h}$ & $1 \mathrm{~h} / \mathrm{h}$ & $1 \mathrm{~h} / \mathrm{h}$ \\
\hline 2 & AIT & 9 & $1 \mathrm{~h} / \mathrm{h}$ & $1 \mathrm{~h} / \mathrm{h}$ & \\
\hline 3 & ACT & 17 & $5 \mathrm{~h} / \mathrm{h} ; 2 \mathrm{CN}(\mathrm{VII})$ & $4 \mathrm{~h} / \mathrm{h} ; 1 \mathrm{CN}(\mathrm{VII})$ & $2 \mathrm{~h} / \mathrm{h}$ \\
\hline 4 & PIT & 3 & $1 \mathrm{~h} / \mathrm{h}$ & $1 \mathrm{~h} / \mathrm{h}$ & $1(\mathrm{~h} / \mathrm{h} \& \mathrm{CN} \mathrm{III)}$ \\
\hline 5 & POT & 4 & $2 \mathrm{~h} / \mathrm{h} ; 2 \mathrm{CN}(\mathrm{III}, \mathrm{VI})$ & $2 \mathrm{~h} / \mathrm{h} ; 1 \mathrm{CN}(\mathrm{III})$ & \\
\hline 6 & SCIT & 8 & $1 \mathrm{CN}(\mathrm{IV})$ & $1 \mathrm{CN}(\mathrm{III})$ & $4 \mathrm{~h} / \mathrm{h} ; 1 \mathrm{~h} / \mathrm{h} \mathrm{\&} \mathrm{CN} \mathrm{III}$ \\
\hline Total & & $11 \mathrm{~h} / \mathrm{h}, 5 \mathrm{CN}$ & $10 \mathrm{~h} / \mathrm{h}, 3 \mathrm{CN}$ & \\
\hline
\end{tabular}

$\mathrm{h} / \mathrm{h}=$ hemiparesis or hemiparesthesias that included allodynia, dysesthesias, numbness, or tingling; neuro defs = neurological deficits.

* Worse neurological status from initial presentation to the most recent clinical follow-up.

date nucleus, putamen, globus pallidus, internal capsule, and anterior thalamus. This region is difficult to reach via approaches such as the transcortical, transsylvian-transinsular, and transcallosal-transventricular because they require a significant amount of transgression of the frontal lobe, insular cortex, and healthy thalamus, respectively. In the current series, 5 CMs (11\%) were located in Region 1. These CMs were all approached via an $\mathrm{OZ}$ craniotomy with a transsylvian supracarotid-infrafrontal dissection (Fig. 2). This route exposes the supracarotid triangle and then works the triangle transfrontally to access the lesion from below. ${ }^{31}$ An OZ craniotomy is critical, because the triangle is entered with a surgical trajectory that is upward and posterior to the frontal lobe in a supraorbital line that parallels the course of the optic nerve. Once the sylvian fissure is widely opened, a proper trajectory is defined and selected to minimize brain transgression and avoid perforators. These perforators are parted and protected from the surgical corridor. The most critical pitfall of this approach is the potential for compromising the perforating arteries, with subsequent internal capsule stroke.

One patient in our series suffered a small internal capsule stroke, presumably from injury to a perforating artery. This patient had transient worsening of hemiparesis that recovered within the next 6 weeks after surgery. Waldron and Lawton ${ }^{31}$ published their experience with 5 patients who had CMs in the anteroinferior basal ganglia and who underwent a supracarotid-infrafrontal approach; 2 of these patients had transient neurological deficits after surgery. Careful handling of perforating vessels is critical. The subarachnoid segments of these perforators within the triangle are dissected to increase their mobility. The entry point can be on the $A_{1}$ or $M_{1}$ side; no matter which entry point is chosen, perforators are present that must be mobilized and protected. A potential limitation to this approach is the difficulty in accessing the superior pole of the CM, which lies in the blind spot of the exposure. This spot is the most sensitive one from a neurological perspective, because the lesion comes closest to the internal capsule here. One of our patients had a residual lesion that required a second-stage operation via the same approach the next day. After the second operation, the patient had no deficits and was discharged home 2 days later. In this case, removal of orbital bone with the OZ craniotomy and intraoperative navigation helped address this limitation.

\section{Region 2 (Medial)}

The medial thalamus was the second-most common location. An AIT approach was performed in all cases (Fig. 3). Two of these cases were situated at the upper part of this region, within the lateral ventricle. After the callosotomy was performed, the hemosiderin ring around the $\mathrm{CM}$ was identified and the lesion was resected. The other 7 lesions were located in the lower part of Region 2, within the third ventricle, requiring further dissection into the third ventricle. There were 2 main surgical corridors for these lesions: transforaminal (3 patients) and transchoroidal (4 patients). The transforaminal corridor gave access to CMs located more anteriorly; the foramen of Monro was opened posteriorly toward the choroidal fissure. The transchoroidal approach was performed through the lateral aspect of the choroid plexus (tela thalami), which is different from previous descriptions. We prefer an incision lateral to the choroid plexus, because it can be used as a buffer between the fornix and the instruments. For the AIT approach, most neurosurgeons still place their patients supine or sitting with the head and neck in the neutral position and the sagittal midline oriented vertically. We prefer to rotate the neck laterally to orient the midline horizontally. A horizontal position is easier on the surgeon's hands, allowing them to work in the same plane. This position necessitates a decision regarding laterality. The head is positioned with the lesion side down. This position works well for lesions located close to the midline, as is the case in Region 2.

\section{Region 3 (Lateral)}

The lateral thalamus was by far the most common location. All lesions in this region were resected through an ACT approach (Fig. 4). This approach has many important advantages compared with others. It avoids a transcortical incision, and gravity retracts the hemisphere to open the interhemispheric fissure. The craniotomy and interhemispheric approach are contralateral to the lesion and the transventricular approach is ipsilateral to the lesion. In contrast to Region 2 (medial), lesions in Region 3 (lateral) require significant retraction of the hemisphere, which risks injury to the parafalcine and the cingulate gyrus. The ACT approach offers a better angle that increases lateral exposure and minimizes the retraction required in the medial hemisphere. In addition, gravity pulls the upside lesion medially into the surgeon's view. This approach was 
used in all Region 3 CMs (17 CMs, 37\%), and there were no neurological complications associated with this procedure. A GTR was obtained in all cases (Video 1).

\section{Region 4 (Posterosuperior)}

The area around Region 4 contains critical anatomical structures, including the medial occipital lobe, posterior corpus callosum, thalamus, posterior cerebral arteries, and the vein of Galen. ${ }^{26,35}$ Surgical approaches to the posterior midline thalamus include the SCIT or transtentorial, PIT, occipital transtentorial, and occipital bitranstentorial/falcine approaches. We believe that the PIT approach offers a superior route to the posterosuperior region of the thalamus; it provides a wider exposure than the infratentorial approach, because the latter is confined by the steep pitch of the tentorium on both sides. The PIT approach was used in all 3 patients with thalamic CMs in Region 4 (Fig. 5). For this approach, the patient is placed lateral with the ipsilateral occipital lobe in a dependent position, using gravity as retraction, similar to the AIT approach. A potential neurological complication is new or worsened visual field deficit, which is often seen with this approach. Chi and Lawton reported their experience with this approach and observed this complication in half of their patients. ${ }^{9}$ This complication is less severe when a lateral position is used, and it is usually reversible. Division of the corpus callosum at its splenium can cause disconnection syndromes. None of these complications were seen in any of our patients.

\section{Region 5 (Lateral Posteroinferior)}

Region 5 of the thalamus projects into the anterior wall of the atrium of the lateral ventricle (Fig. 6). The POT approach through the superior parietal lobe is the preferred route to this area of the ventricle. The cortical incision is made high enough to avoid the optic radiations and posterior enough to avoid the language region. ${ }^{12}$ Other routes to the atrium include the transtemporal ${ }^{10,17}$ and the interhemispheric parietooccipital precuneus (parasplenial) approaches. ${ }^{30}$ However, the former has a high risk of contralateral quadrantanopia and aphasia, whereas the latter requires wider brain retraction and a narrower surgical corridor and angle of approach. ${ }^{17,30}$ All patients with a CM in Region 5 were treated using a POT approach. One patient experienced new onset of aphasia after surgery that partially resolved after a few weeks. There were no surgical complications related to the procedure.

\section{Region 6 (Medial Posteroinferior)}

An SCIT approach was used for all lesions located in Region 6 (Fig. 7). Three different variations of the SCIT approach have been described; they include the median, paramedian, and extreme lateral variations. ${ }^{11}$ We prefer the paramedian SCIT variation; less retraction is needed because the cerebellar surface slopes downward medially to laterally. The patient is placed either supine with the head rotated or in the park-bench position with the lesion side up (Video 2). ${ }^{11}$ After the dura mater is opened, the surface of the cerebellum is gently retracted to expose the cerebellomesencephalic fissure, the ambient cistern, and, further medially, the quadrigeminal cistern. Bridging veins can be encountered, although they are less common with this approach than with a median SCIT. Care must be taken to identify and prevent injury to the vein of Galen, internal cerebral vein, basal veins of Rosenthal, and midbrain branches of the posterior choroidal arteries. The trochlear nerve is identified and mobilized inferiorly (supratrochlear approach). The superior colliculus is exposed in the midline, below the pineal gland. Lateral to these structures, the medial lower pulvinar (Region 6) becomes evident. At times, the posterior parahippocampal gyrus extends medially above the posterior part of the free edge of the tentorium, depending on the width of the posterior incisura. This incisura may partially obscure the upper part of the pulvinar, and the tentorium must be opened. In 1 patient it was necessary to resect the tentorium to better visualize the pulvinar and the CM. In this group there were no surgical complications or new permanent neurological deficits. This area of the thalamus is remarkable in tolerating surgical manipulation. Two patients had worsening of preexisting oculomotor weakness and contralateral hemiparesis that resolved 6-8 weeks after surgery.

\section{Limitations of the Study}

Surgical approaches to these difficult lesions are the result of the extensive experience of the senior author and may not work for every neurosurgeon; therefore, these should not be used as standardized procedures by nonvascular neurosurgeons.

\section{Conclusions}

Thalamic CMs are relatively rare lesions with the potential to cause devastating neurological deficits. Early surgery provides excellent clinical results and eliminates the risk of future hemorrhage. We have presented the largest series to date of thalamic CMs treated surgically. Dividing the thalamus into 6 different regions helps the surgeon to select the ideal surgical approach. Optimal surgical approaches include the OZ transsylvian for Region 1, the AIT for Region 2, the ACT for Region 3, the PIT for Region 4, the POT for Region 5, and the SCIT for Region 6. Intraoperative neuronavigation is essential for approaches to thalamic CMs.

\section{References}

1. Abla AA, Lekovic GP, Turner JD, de Oliveira JG, Porter R, Spetzler RF: Advances in the treatment and outcome of brainstem cavernous malformation surgery: a single-center case series of 300 surgically treated patients. Neurosurgery 68:403-415, 2011

2. Abla AA, Spetzler RF: Brainstem cavernoma surgery: the state of the art. World Neurosurg 80:44-46, 2013

3. Abla AA, Spetzler RF: Cavernous malformations of the thalamus: a relatively rare but controversial entity. World Neurosurg 79:641-644, 2013

4. Abla AA, Spetzler RF: Minimally invasive, but not at the cost of maximally effective, in the surgical removal of brainstem cavernous malformations. World Neurosurg 79:638-640, 2013

5. Abla AA, Spetzler RF, Albuquerque FC: Trans-striatocapsular contralateral interhemispheric resection of anterior inferi- 
or basal ganglia cavernous malformation. World Neurosurg 80:e397-e399, 2013

6. Abla AA, Turner JD, Mitha AP, Lekovic G, Spetzler RF: Surgical approaches to brainstem cavernous malformations. Neurosurg Focus 29(3):E8, 2010

7. Cappabianca P, Spaziante R, de Divitiis E, Villanacci R: Thalamic cavernous malformations. J Neurosurg 75:169-171, 1991

8. Chang EF, Gabriel RA, Potts MB, Berger MS, Lawton MT: Supratentorial cavernous malformations in eloquent and deep locations: surgical approaches and outcomes. Clinical article. J Neurosurg 114:814-827, 2011

9. Chi JH, Lawton MT: Posterior interhemispheric approach: surgical technique, application to vascular lesions, and benefits of gravity retraction. Neurosurgery 59 (1 Suppl 1):ONS41-ONS49, 2006

10. D'Angelo VA, Galarza M, Catapano D, Monte V, Bisceglia M, Carosi I: Lateral ventricle tumors: surgical strategies according to tumor origin and development-a series of 72 cases. Neurosurgery 56 (1 Suppl):36-45, 2005

11. de Oliveira JG, Lekovic GP, Safavi-Abbasi S, Reis CV, Hanel RA, Porter RW, et al: Supracerebellar infratentorial approach to cavernous malformations of the brainstem: surgical variants and clinical experience with 45 patients. Neurosurgery 66:389-399, 2010

12. Ellenbogen RG: Transcortical surgery for lateral ventricular tumors. Neurosurg Focus 10(6):E2, 2001

13. Feiz-Erfan I, Horn EM, Spetzler RF: Transanterior perforating substance approach to the thalamomesencephalic junction. Neurosurgery 63 (1 Suppl 1):ONS69-ONS72, 2008

14. Gross BA, Batjer HH, Awad IA, Bendok BR: Brainstem cavernous malformations. Neurosurgery 64:E805-E818, 2009

15. Gross BA, Batjer HH, Awad IA, Bendok BR: Cavernous malformations of the basal ganglia and thalamus. Neurosurgery 65:7-19, 2009

16. Gross BA, Lin N, Du R, Day AL: The natural history of intracranial cavernous malformations. Neurosurg Focus 30(6):E24, 2011

17. Kawashima M, Li X, Rhoton AL Jr, Ulm AJ, Oka H, Fujii K: Surgical approaches to the atrium of the lateral ventricle: microsurgical anatomy. Surg Neurol 65:436-445, 2006

18. Lawton MT, Golfinos JG, Spetzler RF: The contralateral transcallosal approach: experience with 32 patients. Neurosurgery 39:729-735, 1996

19. Li D, Zhang J, Hao S, Tang J, Xiao X, Wu Z, et al: Surgical treatment and long-term outcomes of thalamic cavernous malformations. World Neurosurg 79:704-713, 2013

20. Mathiesen T, Edner G, Kihlström L: Deep and brainstem cavernomas: a consecutive 8-year series. J Neurosurg 99:3137, 2003

21. Mhoyan A, Fulbright R, Bannykh SI: Cavernous hemangioma of the thalamus. J Neurooncol 71:257, 2005

22. Otani N, Fujioka M, Oracioglu B, Muroi C, Khan N, Roth P, et al: Thalamic cavernous angioma: paraculminar supracerebellar infratentorial transtentorial approach for the safe and complete surgical removal. Acta Neurochir Suppl 103:29_ 36, 2008

23. Pandey P, Westbroek EM, Gooderham PA, Steinberg GK: Cavernous malformation of brainstem, thalamus, and basal ganglia: a series of 176 patients. Neurosurgery 72:573-589, 2013

24. Pozzati E: Thalamic cavernous malformations. Surg Neurol 53:30-40, 2000

25. Rhoton AL: The lateral and third ventricle, in: Cranial and Surgical Approaches. Philadelphia: Lippincott Williams and Wilkins, 2003, pp 235-300

26. Rhoton AL Jr, Yamamoto I, Peace DA: Microsurgery of the third ventricle: Part 2. Operative approaches. Neurosurgery 8:357-373, 1981

27. Roda JM, Alvarez F, Isla A, Blázquez MG: Thalamic cavernous malformation. Case report. J Neurosurg 72:647-649, 1990

28. Sanai N, Mirzadeh Z, Lawton MT: Supracerebellar-supratrochlear and infratentorial-infratrochlear approaches: gravity-dependent variations of the lateral approach over the cerebellum. Neurosurgery 66 (6 Suppl Operative):264-274, 2010

29. Steinberg GK, Chang SD, Gewirtz RJ, Lopez JR: Microsurgical resection of brainstem, thalamic, and basal ganglia angiographically occult vascular malformations. Neurosurgery 46:260-271, 2000

30. Tokunaga K, Tamiya T, Date I: Transient memory disturbance after removal of an intraventricular trigonal meningioma by a parieto-occipital interhemispheric precuneus approach: Case report. Surg Neurol 65:167-169, 2006

31. Waldron JS, Lawton MT: The supracarotid-infrafrontal approach: surgical technique and clinical application to cavernous malformations in the anteroinferior basal ganglia. Neurosurgery 64 (3 Suppl):ons86-ons95, 2009

32. Wang CH, Lin SM, Chen Y, Tseng SH: Multiple deep-seated cavernomas in the third ventricle, hypothalamus and thalamus. Acta Neurochir (Wien) 145:505-508, 2003

33. Washington CW, McCoy KE, Zipfel GJ: Update on the natural history of cavernous malformations and factors predicting aggressive clinical presentation. Neurosurg Focus 29(3):E7, 2010

34. Wen HT, Rhoton AL Jr, Mussi ACM: Surgical anatomy of the brain, in Winn HR (ed): Youmans Neurological Surgery. Philadelphia: Elsevier Saunders, 2011, pp 38-62

35. Yamamoto I, Rhoton AL Jr, Peace DA: Microsurgery of the third ventricle: Part I. Microsurgical anatomy. Neurosurgery 8:334-356, 1981

\section{Author Contributions}

Conception and design: both authors. Acquisition of data: Rangel-Castilla. Analysis and interpretation of data: Rangel-Castilla. Drafting the article: Rangel-Castilla. Critically revising the article: Spetzler. Reviewed submitted version of manuscript: Spetzler. Statistical analysis: Rangel-Castilla. Administrative/technical/ material support: both authors. Study supervision: Spetzler.

\section{Supplemental Information \\ Videos}

Video 1, Media Player. http://mfile.akamai.com/21490/wmv/ digitalwbc.download.akamai.com/21492/wm.digitalsource-naregional/jns14-381_video_1.asx.

Video 1, Quicktime. http://mfile.akamai.com/21488/mov/ digitalwbc.download.akamai.com/21492/qt.digitalsource-global/ jns14-381_video_1.mov.

Video 2, Media Player. http://mfile.akamai.com/21490/wmv/ digitalwbc.download.akamai.com/21492/wm.digitalsource-naregional/jns14-381_video_2.asx.

Video 2, Quicktime. http://mfile.akamai.com/21488/mov/ digitalwbc.download.akamai.com/21492/qt.digitalsource-global/ jns14-381_video_2.mov.

\section{Correspondence}

Robert F. Spetzler, c/o Neuroscience Publications, Barrow Neurological Institute, St. Joseph's Hospital and Medical Center, 350 W. Thomas Rd., Phoenix, AZ 85013.email: neuropub@ dignityhealth.org. 